\title{
Enantioselective Palladium(II)-Catalyzed Borylation
}

Gategory

Metal-Catalyzed

Asymmetric

Synthesis and

Stereoselective

Reactions

\section{Key words}

palladium catalysis

borylation

amides

\section{Synfactith the nom}

Synthetic application:
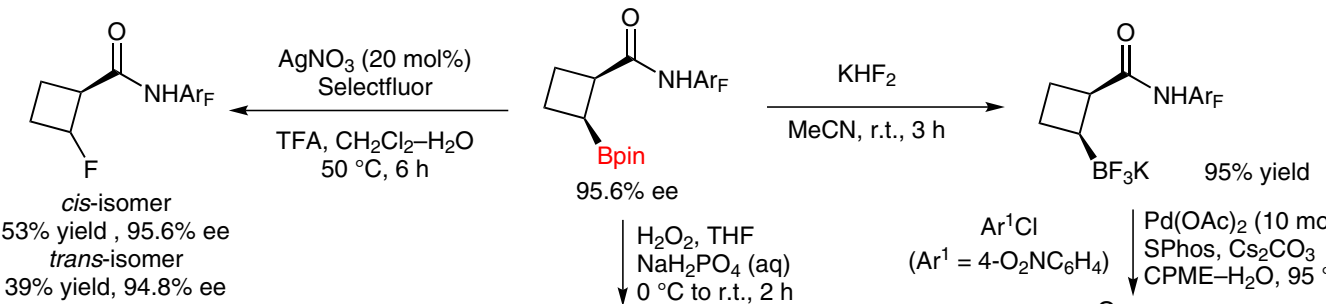

$\mathrm{H}_{2} \mathrm{O}_{2}$, THF $\mathrm{NaH}_{2} \mathrm{PO}_{4}(\mathrm{aq})$ $\checkmark{ }^{\circ} \mathrm{C}$ to r.t., $2 \mathrm{~h}$

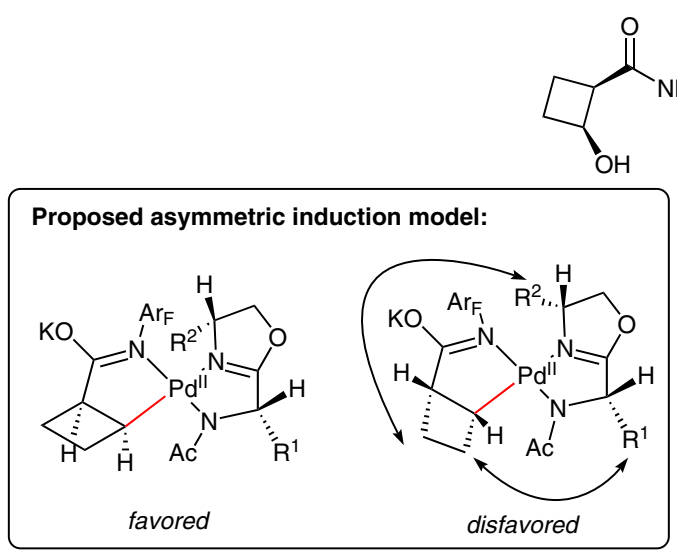

$88 \%$ yield $95.8 \%$ ee<smiles>CC(F)NC(=O)[C@@]1(CNC(F)F)CC[C@@H]1C(=O)NC(F)F</smiles>

$77 \%$ yield $97.4 \%$ ee (with L1)
$52 \%$ yield

$88.3 \%$ ee

(with L1)

solvent $=$ MeCN-DCE (4:1)
Significance: The authors developed a palladium(II)-catalyzed borylation of cyclic amides by using chiral bidentate ligands. A wide variety of borylated cyclobutanes bearing an amide group were obtained with high selectivities.
Comment: A transformation of the product, including the removal of the amide auxiliary, was accomplished to demonstrate the synthetic utility of the reaction. An asymmetric induction model is also proposed.

SYNFACTS Contributors: Hisashi Yamamoto, Yasushi Shimoda

Dol: 10.1055/s-0036-1590457; Reg-No.: H04817SF 